\title{
Understanding Air Pollution from Induced Traffic during and after the Construction of a New Highway: Case Study of Highway 25 in Montreal
}

\author{
Md. Shohel Reza Amin, ${ }^{1}$ Umma Tamima, ${ }^{2}$ and Luis Amador Jimenez ${ }^{2}$ \\ ${ }^{1}$ Civil Engineering (Highways \& Transportation Engineering), Faculty of Engineering, Environment \& Computing, \\ Coventry University, Priory St., Coventry, West Midlands CV1 5FB, UK \\ ${ }^{2}$ Department of Building, Civil and Environmental Engineering, Concordia University, 1515 St. Catherine Ouest, \\ Montréal, QC, Canada H3G 1M8 \\ Correspondence should be addressed to Md. Shohel Reza Amin; ac4569@coventry.ac.uk
}

Received 30 April 2017; Revised 12 September 2017; Accepted 27 September 2017; Published 31 October 2017

Academic Editor: Alexandre De Barros

Copyright (C) 2017 Md. Shohel Reza Amin et al. This is an open access article distributed under the Creative Commons Attribution License, which permits unrestricted use, distribution, and reproduction in any medium, provided the original work is properly cited.

\begin{abstract}
This study demonstrates through a case study that detailed analyses, even after the construction of a project, are feasible using current technologies and available data. A case study of highway 25 is used to illustrate the method and verify the levels of air contaminants from additionally induced traffic during and after the construction of highway. Natural traffic growth was removed from the effect of observed gas emissions by comparing observed levels on other further locations in the same metropolitan area. This study estimates air pollution from the additional traffic during and after the construction of A-25 extension project. $\mathrm{NO}_{2}$ levels were spatially interpolated during peak and off-peak hour traffic and traffic density simulated on the road network for four scenarios. Comparing the four scenarios, it was found that levels of $\mathrm{NO}_{2}$ concentrations were reduced at neighbor areas due to less traffic during the construction period. Levels of $\mathrm{NO}_{2}$ after the construction were higher than those in 2008. The simulated traffic density for four scenarios revealed that traffic density was significantly increased on both arterial and access roads within the close vicinity of the extension project during and after its construction.
\end{abstract}

\section{Introduction}

The construction of highway 25 (A-25) started in 1966 with the goal of enhancing the commercial trade among Montreal, Laval, and Longueuil. This highway is part of the TransCanada corridor and connects two major highways (A-40 with A-20) traversing Montreal. The Ministère des Transports du Québec (MTQ) postponed the construction of A-25 on the locality of Rivére des Prairies because of strong opposition from several citizen groups and business associations. The Green Coalition, an association of many groups and individuals to protect natural environment, opposed the extension of A-25. The association accused that this project did not consider or follow through other alternatives or issues, such as improved freight-rail networks with intermodal nodes or terminals, reserved and separated light rail, transit oriented development, integrated living, and consequences of urban sprawl, and that rather it would destroy green fields and negatively impact the De Montigny Stream Eco-territory [1]. The Groupe en Recherché Urbaine [2] noticed that the project did not address land use changes and air pollution from additional traffic during and after its construction.

The government decided to complete the extension of A25 on 2007 and the project was opened to traffic on May 21, 2011. The project had three main components: (1) freeway and service roads between Boulevard Henri-Bourassa (in Montreal) and Boulevard Gouin (on Rivière des Prairies) with $3 \mathrm{~km}$ length, (2) a bridge known as Olivier Charbonneau (1.2 km length) on Rivére des Prairies, and (3) a highway and service roads between Boulevard Lévesque (Rivière des Prairies) and route A-440 in Laval with $3 \mathrm{~km}$ of length. The main objectives of the project were to improve the travel time 
between North-East Montreal and Laval, to reduce the traffic congestion on major roads (A-440, A-40, A-125, A-19, and A-15) and to support the economic development of the east region in Montreal and Laval [3].

This study presents a framework for future analysis and to understand and illustrate air pollution from the additional traffic during and after the construction of A-25 extension project in Montreal. This study has two objectives: (1) to interpolate the spatial patterns of air pollutants within a close proximity of A-25 extension project in Montreal Island and (2) to estimate the traffic density for each link of Montreal road network within the close proximity of project site for different scenarios in order to understand the change of traffic density during and after the construction of A-25 extension project.

\section{Literature Review}

Nitrogen Oxides (NOx), fine Particulate Matter $\left(\mathrm{PM}_{2.5}\right)$, Volatile Organic Compounds (VOCs), Carbon Monoxide (CO), and Sulphur Dioxide $\left(\mathrm{SO}_{2}\right)$ are the most common air pollutants emitted by vehicles. These air pollutants are also emitted from other anthropogenic sources in urban areas. For example, gasoline and diesel combustions only contribute at most to $16 \%$ and $9 \%$ of $\mathrm{PM}_{2.5}$ in urban areas. In urban and industrial areas, many VOCs are emitted from anthropogenic sources, such as transportation, fossil fuelburning power plants, chemical plants, petroleum refineries, certain construction activities, solid waste disposal, and slash burning [4]. In addition to the anthropogenic sources, many VOCs are produced naturally by vegetation [4]. The $\mathrm{SO}_{2}$ is mainly emitted by fossil fuel combustion, smelting, manufacture of sulphuric acid, conversion of wood pulp to paper, incineration of refuse, and production of elemental sulphur. In urban areas, the majority of $\mathrm{CO}$ emissions come from mobile sources, particularly from the incomplete combustion of vehicle fuels. However, very few air recording stations in Montreal have data on the levels of $\mathrm{CO}$ concentrations. The NOx are created during fuel combustion. Vehicle engines burn a small proportion of the nitrogen that is present in the air plus nitrogen compounds found in vehicle fuels. The air record stations in Montreal have records on the level of concentrations of $\mathrm{NO}_{2}$ for the selected periods before, during and after the construction of A-25 extension project.

Several studies [5-7] analyzed the economic, traffic, and land use impacts of road infrastructure. Some researchers [8, 9] discussed the environmental and ecological effects of constructing road infrastructure. Walton and Shaw [8] discussed the direct and indirect ecological effects of road construction on the landscape, such as effects on both abiotic and biotic components of terrestrial and aquatic ecosystems. Coffin [9] urged that the development of road infrastructure should be examined through a separate system of Environmental Assessment (EA).

Spatial techniques are applied to estimate the concentrations of traffic-related pollutants within the buffer zone of the project sites [3, 10]. Briggs et al. [10] evaluated the use of a GIS-based regression mapping technique to model spatial patterns of the concentrations of $\mathrm{NO}_{2}$ within $300 \mathrm{~m}$ buffer zone of 80 passive sampler sites in Huddersfield, the UK. The model was applied to other urban areas in Sheffield, Northampton, and part of London. This spatial regression model may have applicability in the long-term exposure of traffic-related pollutants; however, it is unable to assess the short-term (e.g., hourly) concentrations of $\mathrm{NO}_{2}$. Chiaburu et al. [3] assessed the local air pollution implications of A-25 expansion project within $5 \mathrm{~km}$ buffer zone of the project site at Montreal Island. Chiaburu et al. [3] focused on only the ozone concentration for determining the baseline scenario. Chiaburu et al. [3] assumed that additional traffic and future economic development would increase the pollution levels by $20 \%$ and $10 \%$ at project site and other adjacent sites, respectively. This general assumption of traffic projection ignored the actual estimated traffic and air pollutants that emitted from projected traffic during and after the construction of road infrastructure.

The air pollution of additional traffic on surrounding areas of new road infrastructure was not addressed in these studies. It is complicated to estimate the air pollution from additional traffic during and after the construction of road infrastructure projects. Huang et al. [11] developed a model for asphalt pavement rehabilitation project of A34 between the Hanford roundabout and the Stoke-on-Trent City boundary in the United Kingdom (UK), estimated the disruption of traffic during construction and maintenance operations using the microsimulation program VISSIM, and finally input the simulated traffic in EnvPro emissions model to estimate emissions from road network and traffic during construction and maintenance operations. Huang et al. [11] simulated the traffic flow on the project site in normal time and during the roadwork based on the knowledge of traffic data and road configuration, but did not consider the project's impact on the surrounding road because of the diverted traffic. Wang and Xie [12] estimated the concentrations of $\mathrm{PM}_{10}, \mathrm{CO}, \mathrm{NO}_{2}$, and $\mathrm{O}_{3}$ on selected twelve avenues in the urban area of Beijing during and before the traffic controlling days of 2008 Olympic Games. Wang and Xie [12] applied the OSPM model to predict the average concentrations and daily variations of these pollutants at street level and validated the predictions with the measurements from mobile-source data. The OSPM model is based on a simplified description of flow and dispersion conditions in street canyons: direct contribution from street traffic, recirculation part of pollutants, and sumup with emissions from other automobile sources [12]. The mobile-source data on different sites of road network can be a very effective source to model and calibrate the long-term assessment of vehicle emissions from the induced traffic due the construction of road infrastructure.

The long-term modeling of traffic-related pollutants requires integration and reliable interface of two separate modeling processes: (1) traffic simulation using travel demand models and (2) emission factors using mobilesource emission models [13]. Traffic simulation and vehicle emissions can be measured at either trip or link level [13]. Bai et al. [13] compared the link-based and trip-based travel data on regional peak period emission records in Sacramento Metropolitan Area and Kern County of California and concluded that link-based method resulted in higher emissions 
than trip-based method. Ito et al. [14] compared different emission records for several prediction years based on trip and link level travel data and found that trip-based traffic data produced consistently lower regional emission estimates.

\section{Methodology}

3.1. Spatial Interpolation of $\mathrm{NO}_{2}$ Concentrations. This study spatially interpolates the levels of $\mathrm{NO}_{2}$ concentrations in the years 2003,2008 , and 2013 to determine changes in air quality during and after the construction of the extension of A25. There are eighteen air record stations located within the island of Montreal and ten stations have records on $\mathrm{NO}_{2}$ concentrations in the years 2003,2008, and 2013. This study uses the hourly levels of $\mathrm{NO}_{2}$ concentrations (parts per billion, $\mathrm{ppb}$ ) that were collected from the Réseau de surveillance de la qualité de l'air of the City of Montreal. Data on hourly levels of $\mathrm{NO}_{2}$ concentrations are categorized into two groups, such as peak hour traffic and off-peak hour traffic data to understand the impact of traffic on the levels of $\mathrm{NO}_{2}$ concentrations.

Geostatistics tools of ArcGIS are applied to spatially interpolate $\mathrm{NO}_{2}$ concentrations assuming that levels of $\mathrm{NO}_{2}$ are absolutely spatial. The geostatistics incorporate different statistical techniques to determine the relationship between spatially distributed values that estimates values at unsampled locations. The fundamental concept of spatial interpolation is that an unknown interpolation parameter is the function of certain statistical parameters [15]. Spatial interpolation was based on the variability between sample locations as a function of the distance. A variogram was used on the interpolation to capture the spatial relationship between the sample values as a function relating the variance of the values to the distance of sample separations [16].

The inverse distance weighting (IDW) and Kriging are most widely used methods for spatial interpolation. The IDW gives more weight to the closest samples and less weight to samples located farther away. The weight for each estimate is inversely proportionate to the power of distance between the sample points [17]. The Kriging uses spatial dependencies of the measured values. This study applies the residuals from the cross-validation procedure to determine the best fitted model for the spatial interpolation of $\mathrm{NO}_{2}$ concentrations. The cross-validation procedure involves computation of meansquared error (MSE) (see (1)), root mean-squared error (RMSE) (see (2)), mean absolute error (MAE) (see (3)), and goodness-of-prediction ( $G$-value) (see (4)). The MSE is a measure of the sum of the squared residuals and is used to determine the appropriate number of nearest neighbors for the methods of IDW and Kriging. The smallest MSE decides the method having the most accurate local or smallscale estimates. The accuracy of the global or large scale estimation is determined by RMSE. The G-value or goodnessof-prediction is a measure of the effectiveness of estimates generated from the model relative to an estimate using only the sample mean. Negative values indicate that the mean would have provided a more accurate estimate.

$$
\mathrm{MSE}=\frac{1}{n} \sum_{i=1}^{n}\left[z\left(x_{i}\right)-\bar{z}\left(x_{i}\right)\right]
$$

$$
\begin{aligned}
\text { RMSE } & =\sqrt{\frac{1}{n} \sum_{i=1}^{n}\left[z\left(x_{i}\right)-\bar{z}\left(x_{i}\right)\right]^{2}} \\
\mathrm{MAE} & =\frac{1}{n} \sum_{i=1}^{n}\left[\left|z\left(x_{i}\right)-\bar{z}\left(x_{i}\right)\right|\right] \\
G & =\left(1-\left\{\frac{\sum_{i=1}^{n}\left[z\left(x_{i}\right)-\bar{z}\left(x_{i}\right)\right]^{2}}{\sum_{i=1}^{n}\left[z\left(x_{i}\right)-\bar{z}\right]^{2}}\right\}\right) * 100,
\end{aligned}
$$

where $z\left(x_{i}\right)$ is the observation values of the studied variable measured at point $x_{i}, \bar{z}\left(x_{i}\right)$ is the mean values of the studied variable measured at point $x_{i}$, and $n$ is the numbers of sample pairs.

3.2. Calculation of Traffic Density. This study simulates the traffic flow on each road segment of the road network in Montreal applying a four-step travel demand model [18]. TransCAD software was used for such purpose. The discrete choice model was applied to estimate the trip generations from different boroughs of the city using disaggregate household or individual level data from the 2008 origin-destination survey [18]. Individual decisions to make trips are aggregated to estimate the total number of trips produced from the boroughs of Montreal [18]. The predicted trips are spatially distributed among boroughs of Montreal with a doubly constrained gravity model. The model balances the trip productions and then factors the calculated attractions so that they normalize to the input attractions. These two steps are then enveloped in an iterative loop until the convergence has been achieved [18]. A multinomial logit (MNL) model is applied to estimate the choice of modes (car driving alone, car share, bus, metro, and bicycle) by travelers assuming that the utility of an alternative mode is a function of the choice determinants, unknown parameters, and an i.i.d. Gumbel-distribution error term [18]. Finally, a Stochastic User Equilibrium (SUE) model simulates the traffic flow on each road segment of the network with a logit model. Such logit model considers the equal level of stochasticity for all route costs (travel time) and has closed form solutions for choice probabilities. The SUE is computed in TransCAD using the Method of Successive Averages (MSA) which utilizes a predetermined sequence of step sizes of the general form given in (5) [19]. Several previous studies applied the MSA to solve SUE problem [20-22].

$$
\alpha_{n}=\frac{k_{1}}{k_{2}+n} \quad \sum_{n=1}^{\infty} \alpha_{n} \longrightarrow \infty \sum_{n=1}^{\infty} \alpha^{2}{ }_{n}<\infty
$$

where $\alpha_{n}$ is step size; $n$ is iteration number; $k_{1}$ and $k_{2}$ are parameters under two conditions: (1) sequence will reach the sought value no matter how far it was started and (2) the variance of the random variable will diminish as the iterations procced [19]. The values of both travel time and capacity of each road link are considered as the input network. The capacity of each road link is calculated based on the Highway Performance Monitoring System Field Manual of Federal Highway Administration [23]. The SUE updates the travel 
TABLE 1: Average hourly concentration of nitrogen dioxide (ppb) at four stations near construction site during off-peak hour traffic.

\begin{tabular}{|c|c|c|c|c|c|c|c|c|c|c|c|}
\hline \multirow{3}{*}{ Months } & \multicolumn{11}{|c|}{ Off-peak hour traffic } \\
\hline & \multicolumn{3}{|c|}{ Station 1} & \multicolumn{3}{|c|}{ Station 3} & \multicolumn{2}{|c|}{ Station $7^{* *}$} & \multicolumn{3}{|c|}{ Station 29} \\
\hline & 2003 & 2008 & 2013 & 2003 & 2008 & 2013 & 2008 & 2013 & 2003 & 2008 & 2013 \\
\hline January & 22.6 & 17.47 & 16.9 & 18.5 & 14 & 14.6 & * & 15.6 & 17.9 & 19.4 & 20.3 \\
\hline February & 24.6 & 19.10 & 22.10 & 20.2 & 15.2 & 14 & 16.8 & 18.4 & 21.6 & 17.8 & 18.7 \\
\hline March & 26 & 18.37 & 21.37 & 22.6 & 14.9 & 13.6 & 17.9 & 18.4 & 24.7 & 19 & 20.4 \\
\hline April & 17.3 & 13.29 & 16.29 & 14.6 & 11.9 & 11.4 & 15.3 & 16.7 & 19.6 & 16.1 & 16.6 \\
\hline May & 16.1 & 12.57 & 15.57 & 13.3 & 10.9 & 14.3 & 10.8 & 12.3 & 21.6 & 12.3 & 15 \\
\hline June & 17.5 & 10.46 & 13.46 & 15.4 & 10.3 & 11.3 & 10 & 12 & 16.6 & 10.9 & 12.6 \\
\hline July & 14.5 & 10.86 & 13.86 & 13.6 & 9.86 & 11.3 & 9.78 & 10.9 & 13.4 & 8.74 & 10.3 \\
\hline August & 14.2 & 11.53 & 14.53 & 11.6 & 9.23 & 11.5 & 9.61 & 10.9 & 13.5 & 10.6 & 11.3 \\
\hline September & 15.7 & 11.27 & 14.27 & 12.2 & 9.81 & 10.7 & 9.89 & 10.1 & 15.1 & 11.1 & 12.1 \\
\hline October & 17.2 & 14.40 & 17.40 & 13.6 & 10.9 & 11.7 & 13.1 & 14.2 & 16.3 & 12.5 & 14.1 \\
\hline November & 19.2 & 15.31 & 18.31 & 12.6 & 10.5 & 11.5 & 12.5 & 13.1 & 16.5 & 14.3 & 16.1 \\
\hline December & $*$ & 17.75 & 20.75 & 18.1 & 12.2 & 13.7 & 13.6 & 17.1 & 20.4 & 14.8 & 17.8 \\
\hline Average & 18.6 & 14.37 & 17.1 & 15.5 & 11.7 & 12.5 & 12.7 & 14.1 & 18.1 & 14 & 15.4 \\
\hline
\end{tabular}

${ }^{*}$ Missing data on average hourly concentration of nitrogen dioxide (ppb); ${ }^{* *}$ Réseau de surveillance de la qualité de l'air of the City of Montreal has no record of nitrogen dioxide (ppb) data at station 7 for the year 2003.

times iteratively based on link performance functions that is formulated by the Bureau of Public Roads.

The traffic density of each road segment of Montreal's road network is estimated based on the simulated traffic flow and average travel speed. The average travel speed $(\mathrm{km} / \mathrm{hr})$ of each road segment is estimated following [24]

$$
\begin{array}{r}
\mathrm{ATS}_{d}=\left[\mathrm{FFS}-0.00776\left(v_{d}+v_{0}\right)-f_{\mathrm{np}}\right] \times 1.609 \\
\forall v_{d} \text { or } v_{0}=\frac{V_{i}}{\mathrm{PHF} \times f_{G} \times f_{\mathrm{HV}}},
\end{array}
$$

where $\mathrm{ATS}_{d}$ is the average travel speed in a particular direction; FFS is the free flow speed in $\mathrm{km} / \mathrm{hr}$; $v_{d}$ is the traffic flow rate for analysis direction; $v_{0}$ is the traffic flow rate for the opposition direction; $f_{\mathrm{np}}$ is the adjustment factor for the percentage of on-passing zones and is considered 0.3; $V_{i}$ is the traffic flow at the analysis direction; PHF is the peak hour factor ( 0.92 for urban traffic); and $f_{G}$ and $f_{\mathrm{HV}}$ are the adjustment factors for grade and heavy-vehicles and considered 1 for level terrain and all flows, respectively [24].

This study has considered two primary factors for simulating traffic density during and after the construction of the A-25 extension project, such as traffic growth during the period of 2003-2013 and additional traffic induced by the A25 extension. The travel demand model estimates the traffic flow and traffic density on each road link of the road network for four scenarios: (1) traffic density in 2003 without A-25 extension, (2) traffic density in 2003 with A-25 extension, (3) traffic density in 2008 during the construction of the A-25 extension project, and (4) traffic density in 2013 after the construction of the A-25. Scenario 2 explains the impact on the traffic density of the surrounding road network if an extension was done in 2003. Scenario 3 accounts for the traffic growth and the inducted traffic during the construction of the A-25 extension. Scenario 4 estimates the traffic density considering both traffic growth and the additional traffic after the construction of the A-25 extension.

\section{Data Analysis}

4.1. Spatial Interpolation of $\mathrm{NO}_{2}$ Concentrations. Data on the levels of $\mathrm{NO}_{2}$ at stations 1, 3, 7, and 29 were analyzed for both peak hour traffic and off-peak hour traffic. These stations are located within the close proximity of the extension project. The levels of $\mathrm{NO}_{2}$ that vehicles emit vary according to time of day, season, and meteorological conditions. Levels are also higher in winter season than in other seasons because of the increased use of heating fuels.

As shown on Tables 1 and 2, the concentration of $\mathrm{NO}_{2}$ at station 1 was increased by $4.6 \%, 3.3 \%$, and $18.9 \%$ during peak hours in 2003, 2008, and 2013, respectively. At station 3, the levels of $\mathrm{NO}_{2}$ were increased by $4.6 \%, 12.6 \%$, and $8.7 \%$ during the traffic rush hours in 2003, 2008, and 2013. At station 29, the increase of $\mathrm{NO}_{2}$ concentration was high that is $12.4 \%$, $9.5 \%$, and $12.8 \%$ during the traffic rush hours in 2003, 2008, and 2013. Insignificant increases of $\mathrm{NO}_{2}$ were observed at station 7 during the same years.

During the winter season, the levels of $\mathrm{NO}_{2}$ that vehicles emit were significantly increased at all stations during the selected years (Tables 1 and 2). The increase of $\mathrm{NO}_{2}$ levels was considerably higher during peak hour traffic as compared to the off-peak hour traffic during the winter seasons. This implies that higher traffic on the streets resulted in higher use of heating fuels during the winter seasons. For example, the level of $\mathrm{NO}_{2}$ at station 1 was increased by $31.1 \%, 26.5 \%$, and $18.9 \%$ during the off-peak hours of winter seasons in 2003, 2008, and 2013, respectively (Table 1). During the peak hours of winter seasons, the levels of $\mathrm{NO}_{2}$ were increased by $38.5 \%, 33.5 \%$, and $19.1 \%$ in 2003,2008 , and 2013 , respectively (Table 2). 
TABLE 2: Average hourly concentration of nitrogen dioxide (ppb) at four stations near to construction site during peak-hour traffic.

\begin{tabular}{|c|c|c|c|c|c|c|c|c|c|c|c|}
\hline \multirow{3}{*}{ Months } & \multicolumn{11}{|c|}{ Peak hour traffic } \\
\hline & \multicolumn{3}{|c|}{ Station 1} & \multicolumn{3}{|c|}{ Station 3} & \multicolumn{2}{|c|}{ Station $7^{* *}$} & \multicolumn{3}{|c|}{ Station 29} \\
\hline & 2003 & 2008 & 2013 & 2003 & 2008 & 2013 & 2008 & 2013 & 2003 & 2008 & 2013 \\
\hline January & 27.3 & 20.7 & 20.1 & 21.9 & 17.1 & 20.4 & * & 19.2 & 22.3 & 22.5 & 24.4 \\
\hline February & 27 & 20 & 26 & 22.7 & 17 & 15.7 & 19.5 & 20 & 23.3 & 21.2 & 22.1 \\
\hline March & 26.6 & 18.6 & 24.6 & 22.5 & 14.5 & 14.5 & 17.1 & 18.2 & 26.9 & 19.3 & 23.2 \\
\hline April & 17.6 & 12.7 & 18.7 & 14.9 & 11 & 11.6 & 13.3 & 16.1 & 21 & 15.7 & 18 \\
\hline May & 13.6 & 10.5 & 16.5 & 12.2 & 9.34 & 12.8 & 8.52 & 9.21 & 21.8 & 11.3 & 14.8 \\
\hline June & 15.2 & 9.4 & 15.4 & 14.2 & 9.67 & 10.6 & 8.84 & 10 & 16.5 & 10.3 & 12.3 \\
\hline July & 13.1 & 9.18 & 15.2 & 11.9 & 9.2 & 9.91 & 8.4 & 9.32 & 14.2 & 8.8 & 10 \\
\hline August & 14.3 & 9.37 & 15.4 & 11.7 & 7.78 & 11.3 & 8.16 & 9.57 & 15 & 10.2 & 11.3 \\
\hline September & 16.4 & 12.6 & 18.6 & 12.9 & 10.2 & 11.2 & 10.6 & 12.7 & 18 & 13.1 & 13.6 \\
\hline October & 20.2 & 16.1 & 22.1 & 16.1 & 24.5 & 13.5 & 14.4 & 15.8 & 20.5 & 15.1 & 16.4 \\
\hline November & 23 & 18.9 & 24.9 & 14.8 & 12.2 & 14.6 & 14.4 & 16.8 & 20.9 & 17.5 & 21.5 \\
\hline December & * & 20 & 26 & 19.1 & 14.8 & 16.4 & 16.4 & 21 & 23.9 & 18.5 & 21.4 \\
\hline Average & 19.5 & 14.8 & 20.3 & 16.2 & 13.1 & 13.6 & 12.7 & 14.8 & 20.3 & 15.3 & 17.4 \\
\hline
\end{tabular}

${ }^{*}$ Missing data on average hourly concentration of nitrogen dioxide (ppb); ${ }^{* *}$ Réseau de surveillance de la qualité de l'air of the City of Montreal has no record of nitrogen dioxide (ppb) data at station 7 for the year 2003 .

This temporal analyses help to understand the levels of $\mathrm{NO}_{2}$ before, during and after the construction of the $\mathrm{A}-25$ at the selected stations. At all stations, the levels of $\mathrm{NO}_{2}$ were decreased during the period of 2003-2008 and increased during the period of 2008-2013 (Tables 1 and 2). The diversion of traffic due to the construction of A-25 extension project resulted in decrease of $\mathrm{NO}_{2}$ levels in 2008. The levels of $\mathrm{NO}_{2}$ were increased in 2013 compared to the concentrations levels in 2008 because of the additional traffic attracted to the newly constructed A-25 extension and the surrounding road network (Tables 1 and 2). The levels of $\mathrm{NO}_{2}$ in 2013 were lower than that in 2003, although there were additional traffics and the overall traffic volume was increased on the Montreal road network during the ten years (Tables 1 and 2). This resulted from the government's ongoing initiative to promote mass transit and to reduce vehicle emissions as stated by the Greater Montreal Area Transport Plan, 2000.

There is a probability that the similar changes in $\mathrm{NO}_{2}$ levels were observed at the remaining areas of Montreal during the selected years. This study analyzes the spatial patterns of $\mathrm{NO}_{2}$ levels in Montreal during the peak hour and off-peak hour traffic by applying the IDW and Kriging spatial interpolation methods. The IDW is identified as the best fitted model for the spatial interpolation of $\mathrm{NO}_{2}$ levels by applying the cross-validation tests.

The spatial patterns of $\mathrm{NO}_{2}$ levels during peak hour traffic in 2003 explains that the levels of $\mathrm{NO}_{2}$ were between 18.29 and $25.07 \mathrm{ppb}$ within $5 \mathrm{~km}$ distance of the A-25 at the northeastern area between A-25 and A-40 (Figure 1). However, the levels of $\mathrm{NO}_{2}$ were between 14.9 and $18.28 \mathrm{ppb}$ and 11.51 and $14.89 \mathrm{ppb}$ within 0 to $2 \mathrm{~km}$ and 2 to $4 \mathrm{~km}$ distance of the project's site at the north-western area between A-25 and A-40 (Figure 1). Traffic traveling from north shore to south shore of Montreal by A-20 and A-25 diverted to A125 and Avenue Papineau because of the existence of Pont Pie $I X$ and the bridge Papineau Leblanc on Rivière des Prairies.
On the southern side of $\mathrm{A}-25$, the levels of $\mathrm{NO}_{2}$ reached 18.29 to $25.07 \mathrm{ppb}$ within $5 \mathrm{~km}$ (Figure 1). The levels of $\mathrm{NO}_{2}$ were increasing on south-side of A- 25 because of more urban traffic in the Montreal Island. The 2003 O-D in Montreal Metropolitan Area estimated that there were 6.4 million vehicle trips in the metropolitan area of which only 1.2 million were made by public transport during a typical day of the week. It also identified that the share of trips made by public transport was reduced from $25.7 \%$ in 1987 to $18.9 \%$ in 2003. The increase of car trips and their prominent role on urban traffic resulted in high levels of $\mathrm{NO}_{2}$ within the close proximity of downtown Montreal.

During the peak hours in 2008, the levels of $\mathrm{NO}_{2}$ lay to $9.3-14 \mathrm{ppb}$ within $2 \mathrm{~km}$ distance of the project site at the north-western and south-western sides between A-25 and A40 (Figure 2). The levels of $\mathrm{NO}_{2}$ were reduced by somewhere between 30.57 and $60.21 \%$ in 2008 within a $2 \mathrm{~km}$ buffer zone of the project site as compared to that in 2003 (Figure 2). The levels of $\mathrm{NO}_{2}$ were further reduced up to $9.3 \mathrm{ppb}$ within $2-5 \mathrm{~km}$ distance of project site at the north-western side between A-25 and A-40 (Figure 2). A larger region swath at the south side of A-25 has the $15-18 \mathrm{ppb}$ level of $\mathrm{NO}_{2}$ during the peak hours traffic in 2008 (Figure 2). These levels of $\mathrm{NO}_{2}$ were reduced by up to $22 \%$ as compared to those in 2003 at the same region (Figures 1 and 2). During the construction process of the extension project, the levels of $\mathrm{NO}_{2}$ were reduced in the close proximity to highway 25 due to the less traffic.

Traffic flow was increased in close proximity to the project site after the opening of highway 25 extension on 2011. Higher traffics resulted in higher levels of $\mathrm{NO}_{2}$ concentrations. The levels of $\mathrm{NO}_{2}$ were up to $17 \mathrm{ppb}$ within $1 \mathrm{~km}$ distance of the project site at the north-western side between A-25 and A-40 (Figure 3). The levels of $\mathrm{NO}_{2}$ were increased up to $20 \mathrm{ppb}$ within $1-5 \mathrm{~km}$ distance on the both side of A-25. These levels of $\mathrm{NO}_{2}$ were higher than that in 2008 but lower than 


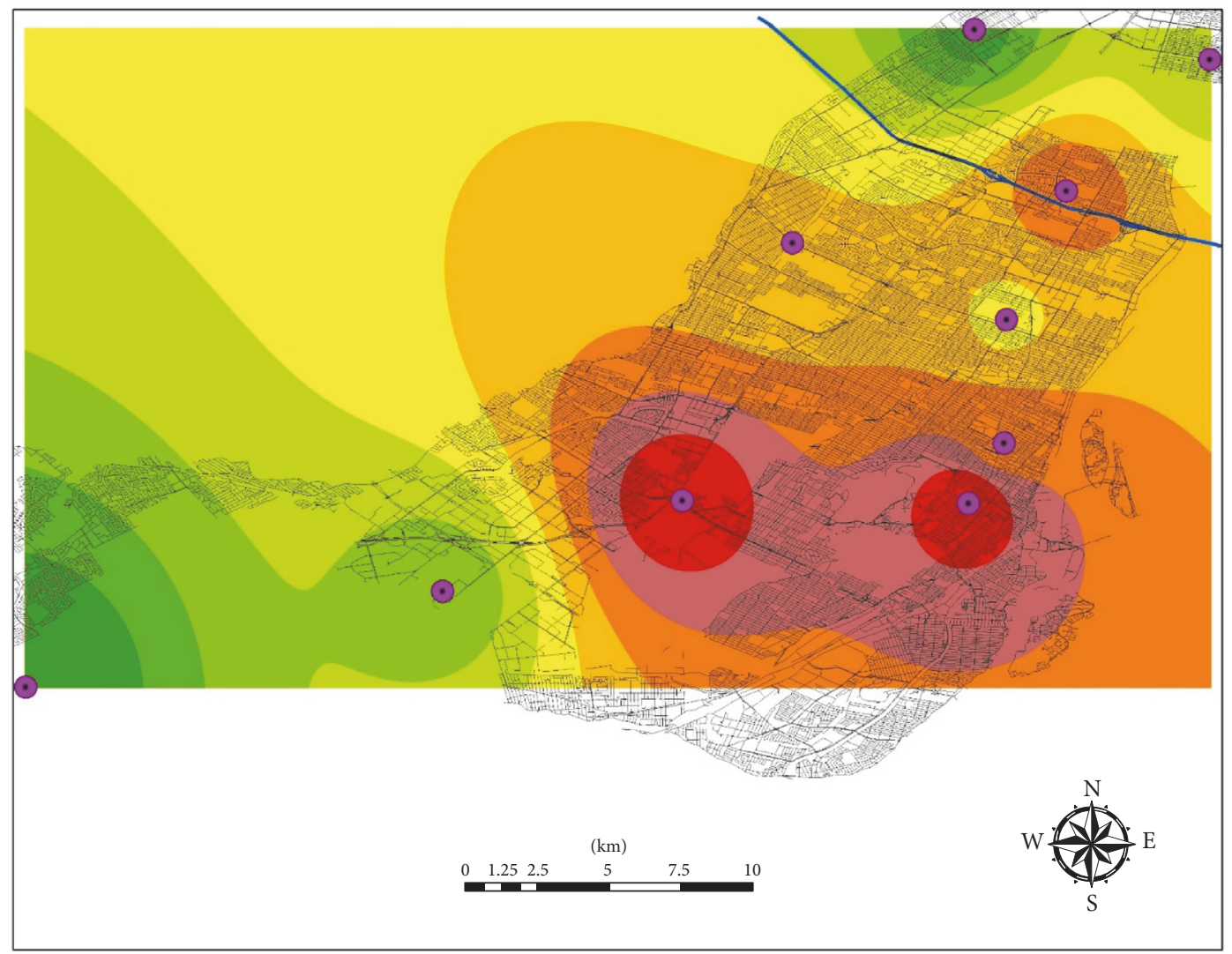

Air record stations

$16.13-18.14$

City of Montreal road network

$18.15-20.15$

Autoroute 25

Average hourly NO2 (PPB) during peak hour traffic, 2003

20.16-22.17

$22.18-24.18$

24.19-26.20

$10.07-12.09$

$12.10-14.11$

$14.12-16.12$

$26.21-28.22$

FIGURE 1: Spatial interpolation of average hourly concentration (ppb) of $\mathrm{NO}_{2}$ during peak hour traffic in 2003.

those found in 2003 (Figure 3). The levels of $\mathrm{NO}_{2}$ in the remaining areas of Montreal were almost unchanged during the peak hour in 2008 and 2013. The spatial patterns of $\mathrm{NO}_{2}$ concentrations during the off-peak hours represent similar distributions of $\mathrm{NO}_{2}$ concentrations in 2003, 2008, and 2013.

The findings from the spatial analyses of $\mathrm{NO}_{2}$ levels support the hypothesis that $\mathrm{NO}_{2}$ concentrations resulted from the additional traffic after the construction of A-25 expansion project.

\subsection{Construction of A-25 Extension Project and Its Impact on} Traffic Density. The coefficients of a logistic discrete choice model of trip generation estimated the increase of working and business trips with increasing number of persons per households, but education oriented trips decreased with more people per households during both peak and off-peak hours [18]. A doubly constrained gravity model spatially distributed the trips among boroughs. For example, a total of 132029 trips were generated from Ville-Marie borough in an average day of the year 2013 and 20 percent of these trips were terminated within the same borough [18]. The MNL models estimated that the travel time was inversely related to the utility of all modes except in the case of car-share riding [18]. Finally, traffic density on each road segment of Montreal was estimated based on (5) and (6). The estimated traffic density on Montreal roads network in 2003 is shown in Figure 4.

Traffic density on each road link was simulated for four scenarios (Figures 4-7) in order to understand the change of traffic density from the construction of A-25. The traffic density for scenarios 2, 3, and 4 was compared with the base scenario (Figure 4) in order to understand the changes of traffic density for different scenarios (Figures 8, 10, and 11).

Significant changes in traffic density (2-5\%) were observed along the highway that connects Laval and Longueuil for scenario 2 as compared to scenario 1 (Figure 8). The traffic density was also increased by $4-5 \%$ at the north-western part of Montreal. The impact of A-25 extension was also observed on the traffic density of arterials and local roads of Montreal (Figure 8). Roads between Boulevard Pie-IX (A 125) and A-25 were increased between 2 and 5\% because of 


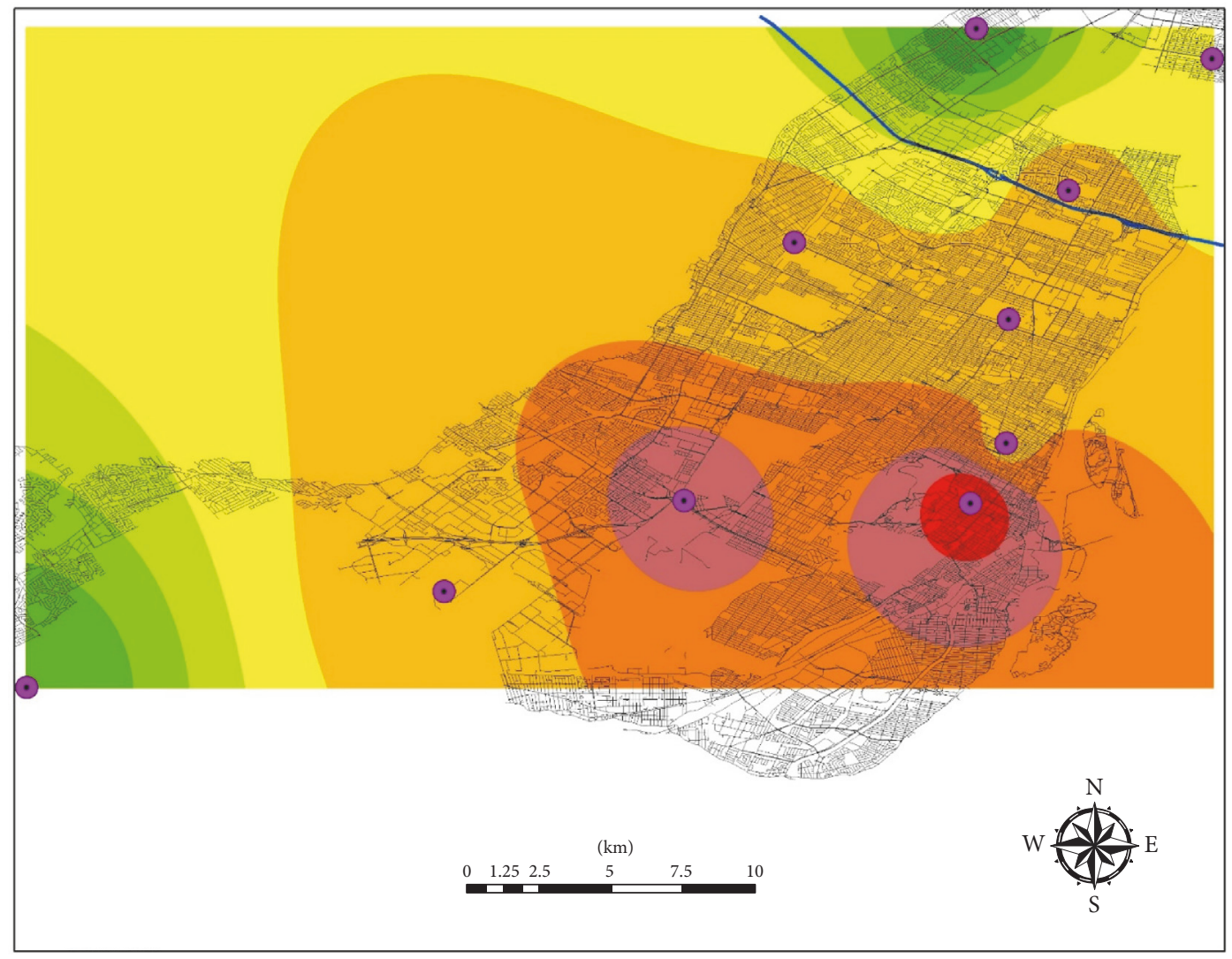

- Air record stations

City of Montreal road network Autoroute 25

Average hourly NO2 (PPB) during peak hour traffic, 2008
$5.00-6.95$
$6.96-8.91$
$8.92-10.87$

$10.88-12.83$

$12.84-14.78$

$14.79-16.74$

$16.75-18.70$

$18.71-20.66$

$20.67-22.62$

FIGURE 2: Spatial interpolation of average hourly concentration (ppb) of $\mathrm{NO}_{2}$ during peak hour traffic in 2008.

the shift of traffic towards A-25 to avoid traffic congestion. Significant reduction of traffic (up to $-5 \%$ ) was observed on roads between Avenue Papineau (A 19) and Boulevard PieIX (A 125) to avoid traffic congestion (traffic density 12-16, LOS C) on the Avenue Papineau (A 19) and its close proximity (Figure 4). The redistribution of traffic for scenario 2 results in less traffic congestion on A-25, Boulevard Pie-IX (A 125), Avenue Papineau (A 19), and other arterials and collector roads in close proximity of these highways (Figure 5).

For scenario 2, traffic density was increased by $5 \%$ at the southern part and up to $4 \%$ at the northern part of the borough of Montréal Nord as compared to scenario 1 (Figure 8). The northern part of this borough is dominated by underdeveloped land (Figure 9). Traffic density of arterials and local roads in the boroughs of Rivière-des-Prairies/Pointeaux-Trembles, Montréal Nord, Saint-Léonard, Rosemont/La Petite Patrie and Mercier/Hochelaga-Maisonneuve showed increases of up to $4 \%$ if the A-25 extension existed in 2003 (Figure 8). Increases in traffic density on arterials and local roads in the close proximity of highways were also observed.
More trips were produced and attracted in these boroughs because of the high building density and residential land use (Figure 9). Insignificant changes (0-2\%) of traffic density were observed on local roads in the northern part of the borough of Mercier/Hochelaga-Maisonneuve and the southern part of the borough of Anjou located at the north-eastern part of Montreal (Figure 8). Major parts of Anjou borough were vacant lands and it is more likely that this area had less change of traffic density irrespective of the construction of A-25 extension (Figure 9). Mixed land use is dominant in Mercier/Hochelaga-Maisonneuve (Figure 9). Low to medium levels of $\mathrm{NO}_{2}$ were observed in this borough in 2003. The levels of $\mathrm{NO}_{2}$ were high in these boroughs represented a strong positive correlation between the additional traffic of the A-25 extension and vehicle concentrations.

Traffic density was increased on all roads of Montreal for traffic growth during the period 2003-2008. The construction of the A-25 extension influenced the traffic density of surrounding road links for scenario 3 (Figure 6). For example, traffic density was increased somewhere between 4 and $8 \%$ 


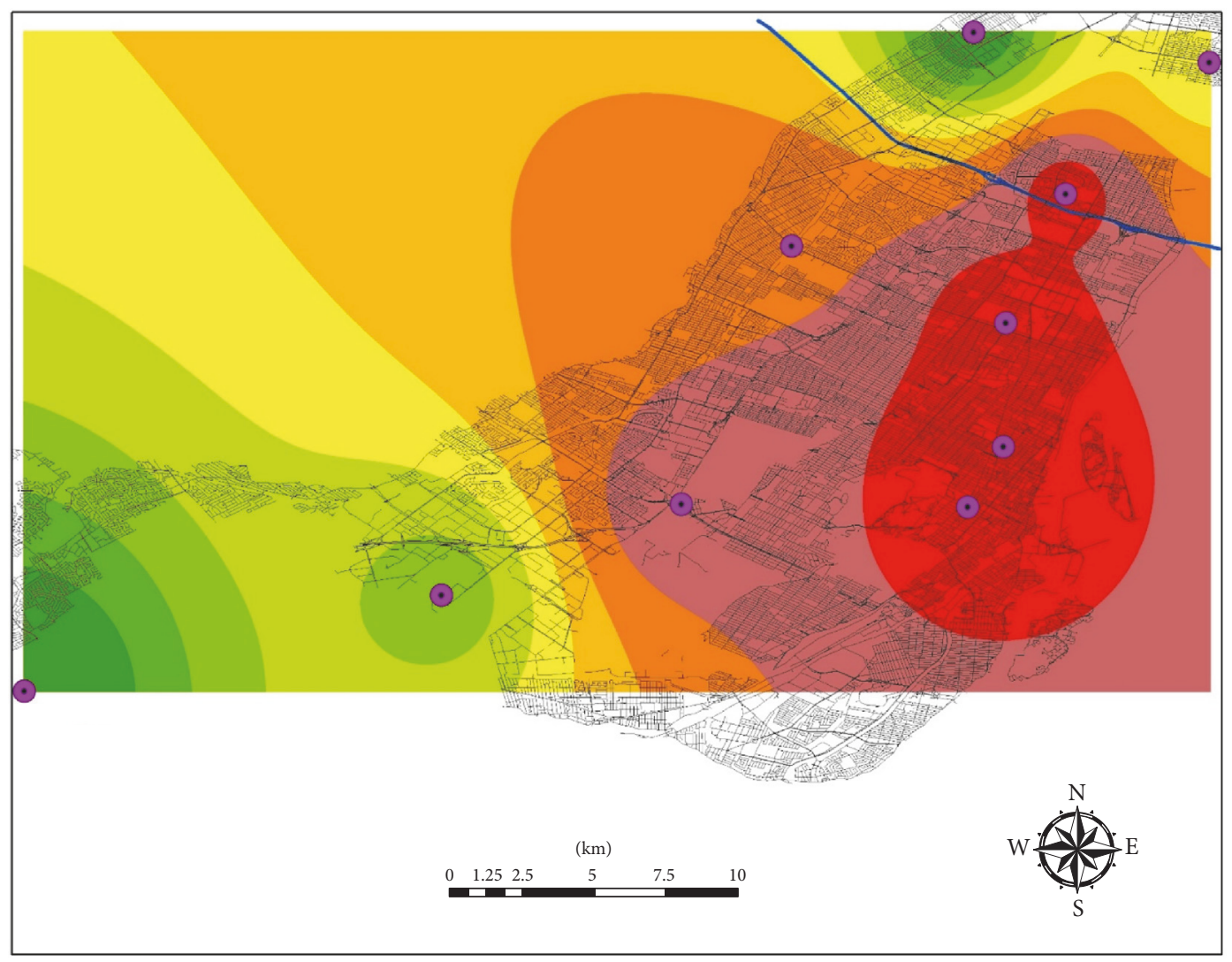

- Air record stations

City of Montreal road network

Autoroute 25

Average hourly NO2 (PPB) during peak hour traffic, 2013

$7.11-8.61$
$\square .62-10.11$
$\square \quad 10.12-11.61$
$11.62-13.12$

$13.13-14.62$

$14.63-16.12$

$16.13-17.63$

$17.64-19.13$

$19.14-20.64$

FIGURE 3: Spatial interpolation of average hourly concentration (ppb) of $\mathrm{NO}_{2}$ during peak hour traffic in 2013.

on the highway connecting Laval and Longueuil, for scenario 3 that was up to $3 \%$ higher than the change of traffic density observed for scenario 2 (Figures 8 and 10). The change of traffic density was up to $8 \%$ because more trip was generated by population growth, higher building density, and change in land uses. Significant changes (up to $8 \%$ ) in traffic density were also observed on arterial and collector roads that are in close proximity to A-25 (Figure 10). Highest increase of traffic density was observed on the roads between Avenue Papineau (A 19) and Boulevard Pie-IX (A 125) and between Boulevard Pie-IX (A 125) and A-25 (Figure 10). Traffic density was increased significantly on these roads because of the diversion of traffic from the construction zone of the A-25. Traffic density on roads of Mercier/Hochelaga-Maisonneuve was significantly increased during the construction of the A-25 extension project (Figure 10). Roads that are located within a $5 \mathrm{~km}$ buffer zone of the A-25 observed an increase of 6 to $8 \%$ in traffic density (Figure 10). Significant increase of traffic density was also observed on the arterial roads of this area. For example, traffic density was increased by as much as an $8 \%$ on more than half of the arterial roads in this borough (Figure 10). On the other hand, traffic density was increased between 2 to $4 \%$ on the collectors and local roads except in the case of roads at the northern side of Mercier/Hochelaga-Maisonneuve boroughs (Figure 10). Traffic density was increased by $4-6 \%$ on the local roads at the eastern side of Boulevard Henri Bourassa because of high residential density (Figures 9 and 10).

In the year 2013, traffic density was significantly increased on the A-25, especially on the segments between Boulevard Gouin East and Boulevard Henry Bourassa East (Figures 7 and 11). Traffic density was increased by $10-12 \%$ on the portion of the A-25 connecting Montreal with Laval and Longueuil after the opening when comparing to the base scenario (Figures 4,7 , and 11). This is the highest increase of traffic density as compared to other scenarios (Figures 8, 10, and 11). The 

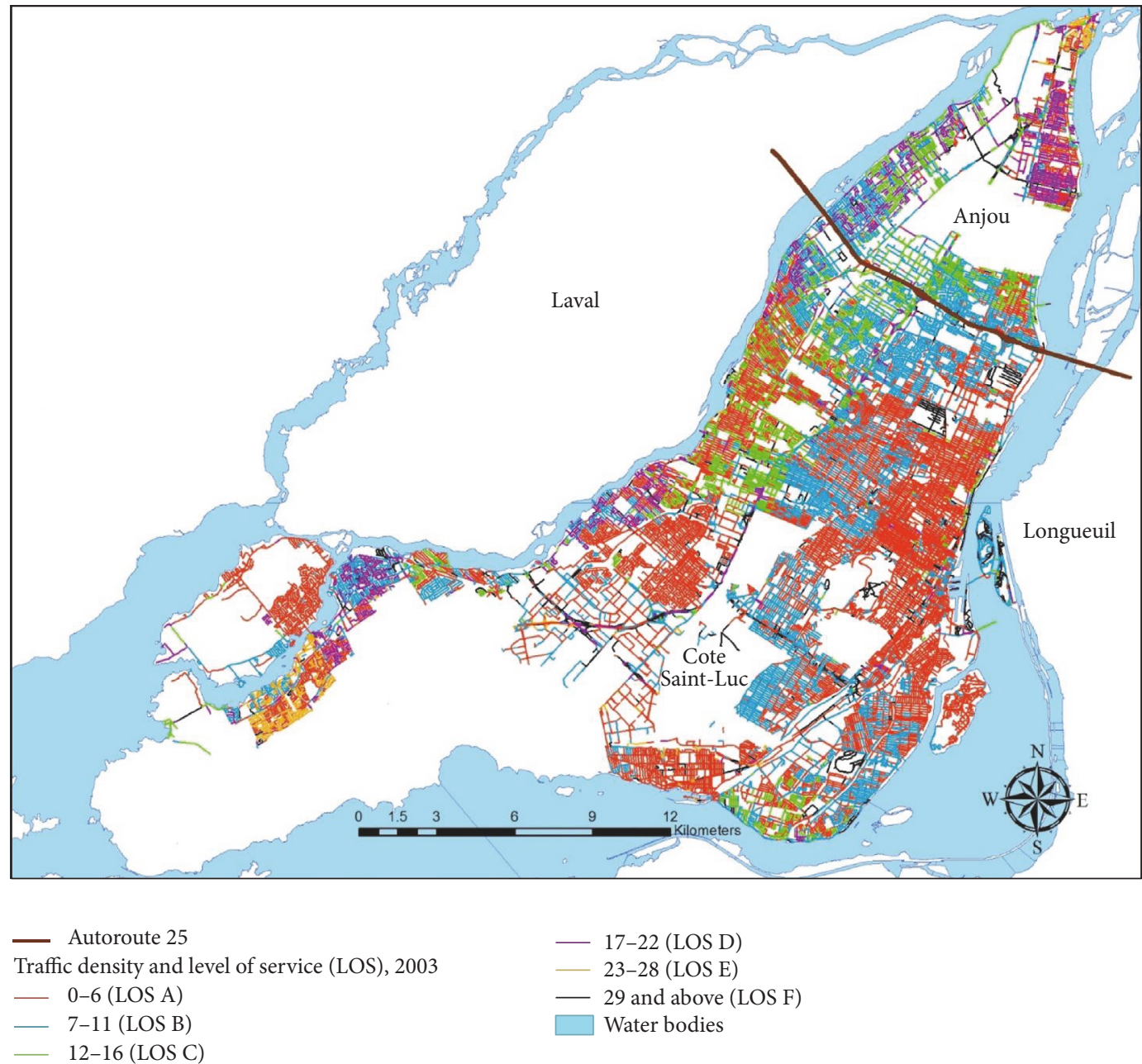

Figure 4: Traffic density (vehicles per km) and level of service of road network in the City of Montreal, 2003 (scenario 1).

increased traffic density resulted from the combined effects of traffic growth during 2003 and 2013 and the opening of the A-25 project.

Significant increase of traffic was observed in Montréal Nord, Anjou, and Rivière-des-Prairies/Pointe-aux-Trembles boroughs (Figure 11). Traffic density at the northern part of Montréal Nord, close to the A-25 extension project, was increased by $10-12 \%$ (Figure 11). The southern part of Montréal Nord, close to A-125 (Boulevard Pie-IX), observed comparatively less increase of traffic density, that is, 4-6\% (Figure 11). Similarly, traffic density was significantly increased by 10 to $12 \%$ on the roads located between the A25 and Boulevard Armand Bombardier within the borough of Rivière-des-Prairies/Pointe-aux-Trembles (Figure 11). Boulevard Louis $h$. Lafontaine observed an increase of up to $12 \%$ traffic density for scenario 4 . Local roads, in close proximity to A-25, observed up to $12 \%$ increase in traffic density after the opening of A-25 extension project (Figure 11). The Boulevard Henri Bourassa East experienced a $12 \%$ increase in traffic density in 2013 (Figure 11). Traffic density on the access roads at the western-side of Boulevard Henri Bourassa East was increased at a higher rate as compared to those at the easternside of this boulevard (Figure 11). These changes were the product of the additional traffic from the opening of the A25 extension in the vicinity of the project area.

\section{Limitations}

It is difficult to argue that increases in the levels of $\mathrm{NO}_{2}$ concentrations were a consequence of the additional traffic resulting from the construction of A-25 extension project. The major limitation of this study is to integrate the simulated traffic and vehicle emissions. The mobile-source data could be an effective solution; however, estimation of traffic-related pollutants during a long-period of time for different scenarios on a large geographical area is very difficult to attain. Nitrogen Oxides (NOx), fine Particulate Matter $\left(\mathrm{PM}_{2.5}\right)$, Volatile Organic Compounds (VOCs), Carbon Monoxide (CO), and Sulphur Dioxide $\left(\mathrm{SO}_{2}\right)$ are the most common air pollutants emitted by vehicles but there are other anthropogenic sources that generate these pollutants. During the construction period, air pollutants were also emitted from construction 


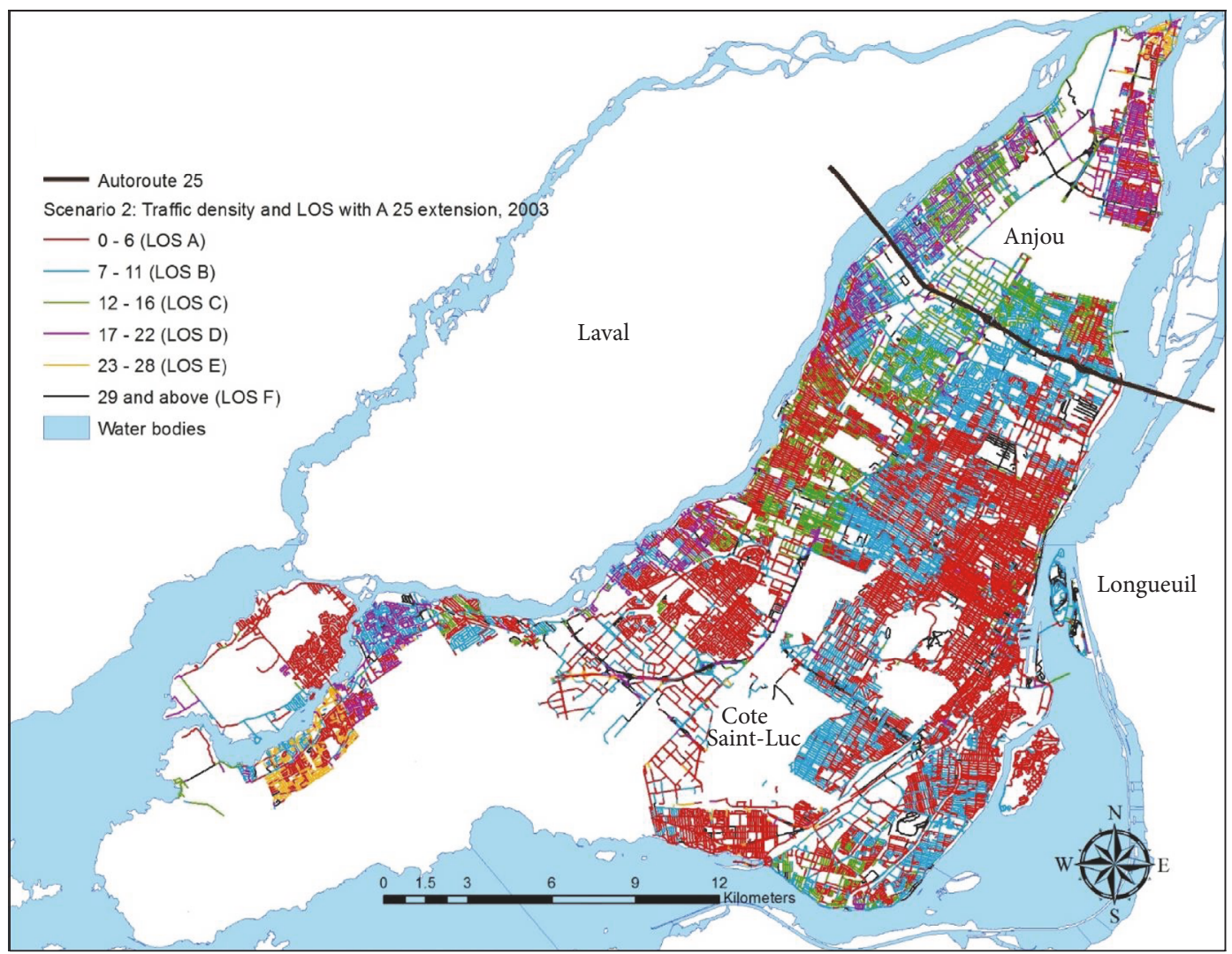

Figure 5: Traffic density (vehicles per km) and level of service of road network in the City of Montreal, 2003 (scenario 2).

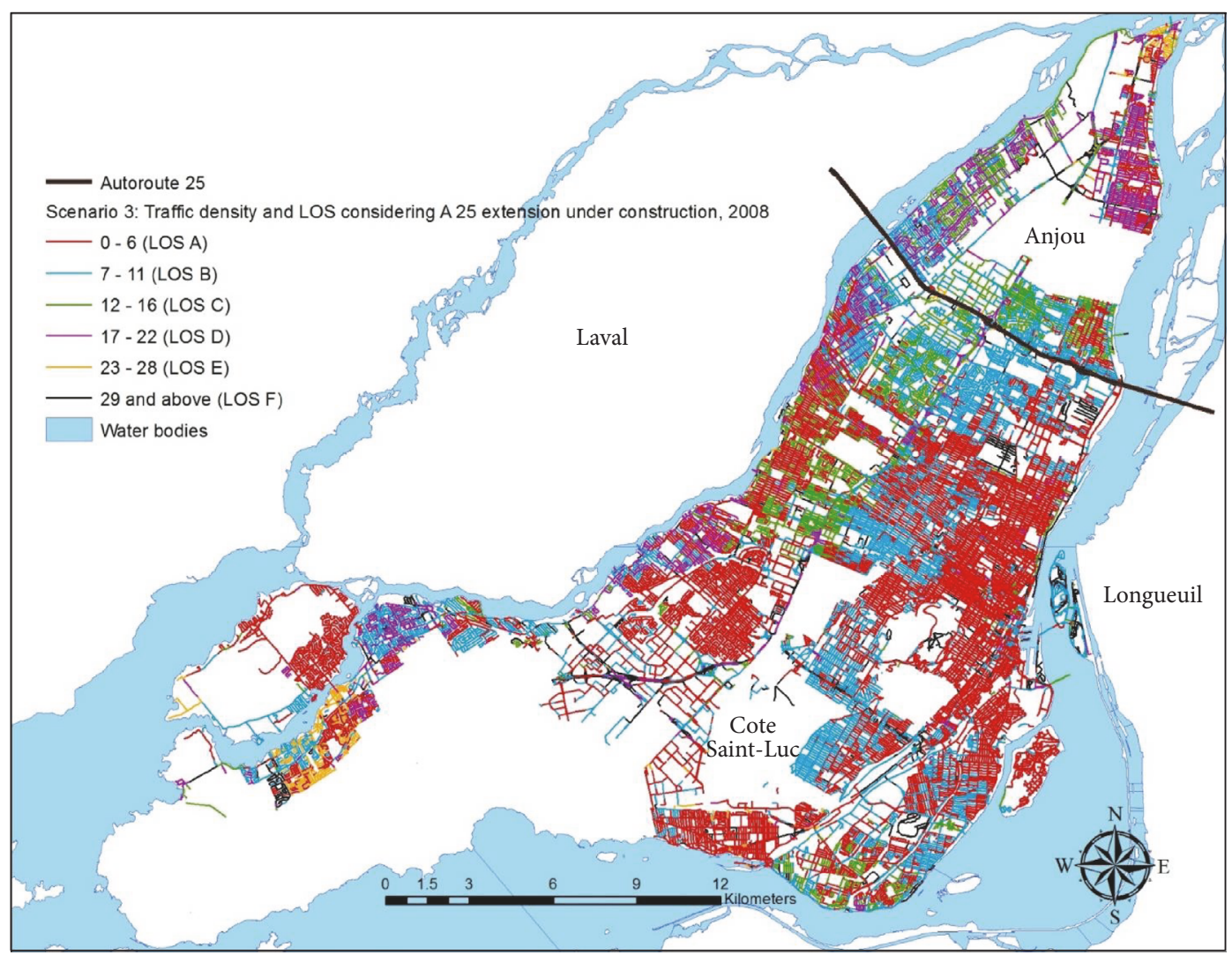

FiguRE 6: Traffic density (vehicles per km) and level of service of road network in the City of Montreal, 2008 (scenario 3). 


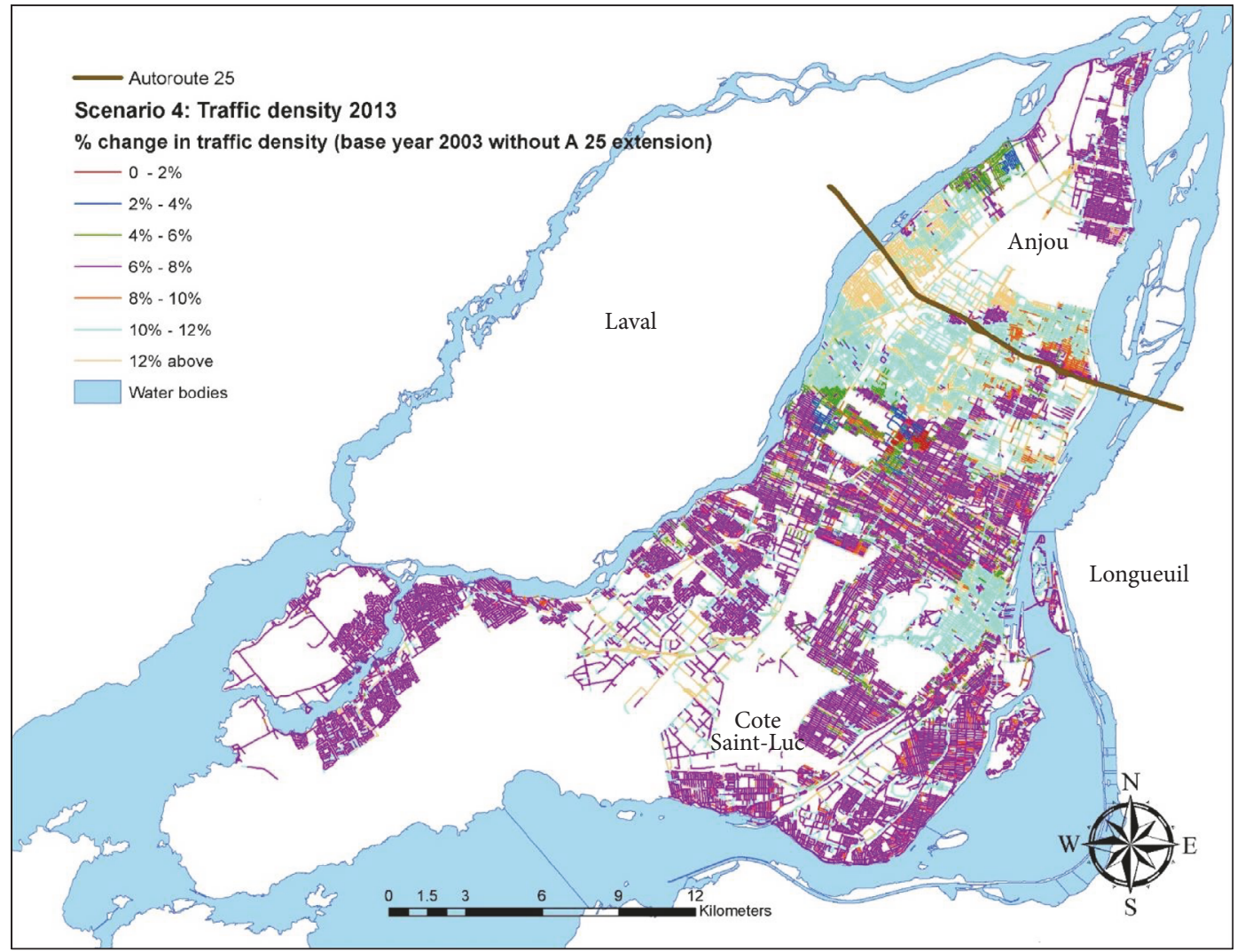

Figure 7: Traffic density (vehicles per km) and level of service of road network in the City of Montreal, 2013 (scenario 4).

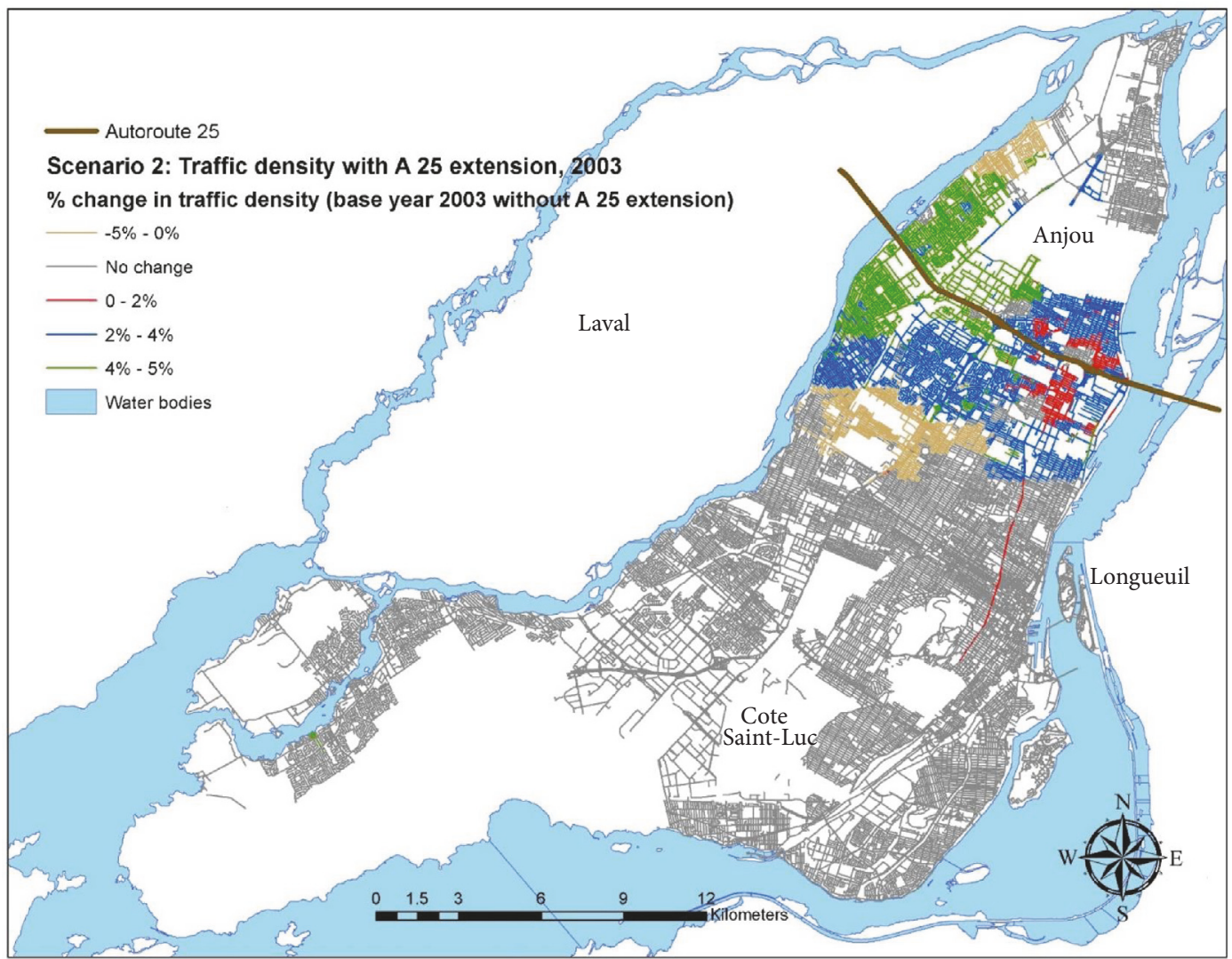

FIGURE 8: Percentage change in traffic density (vehicles per $\mathrm{km}$ ) at scenario 2 comparing to scenario 1. 


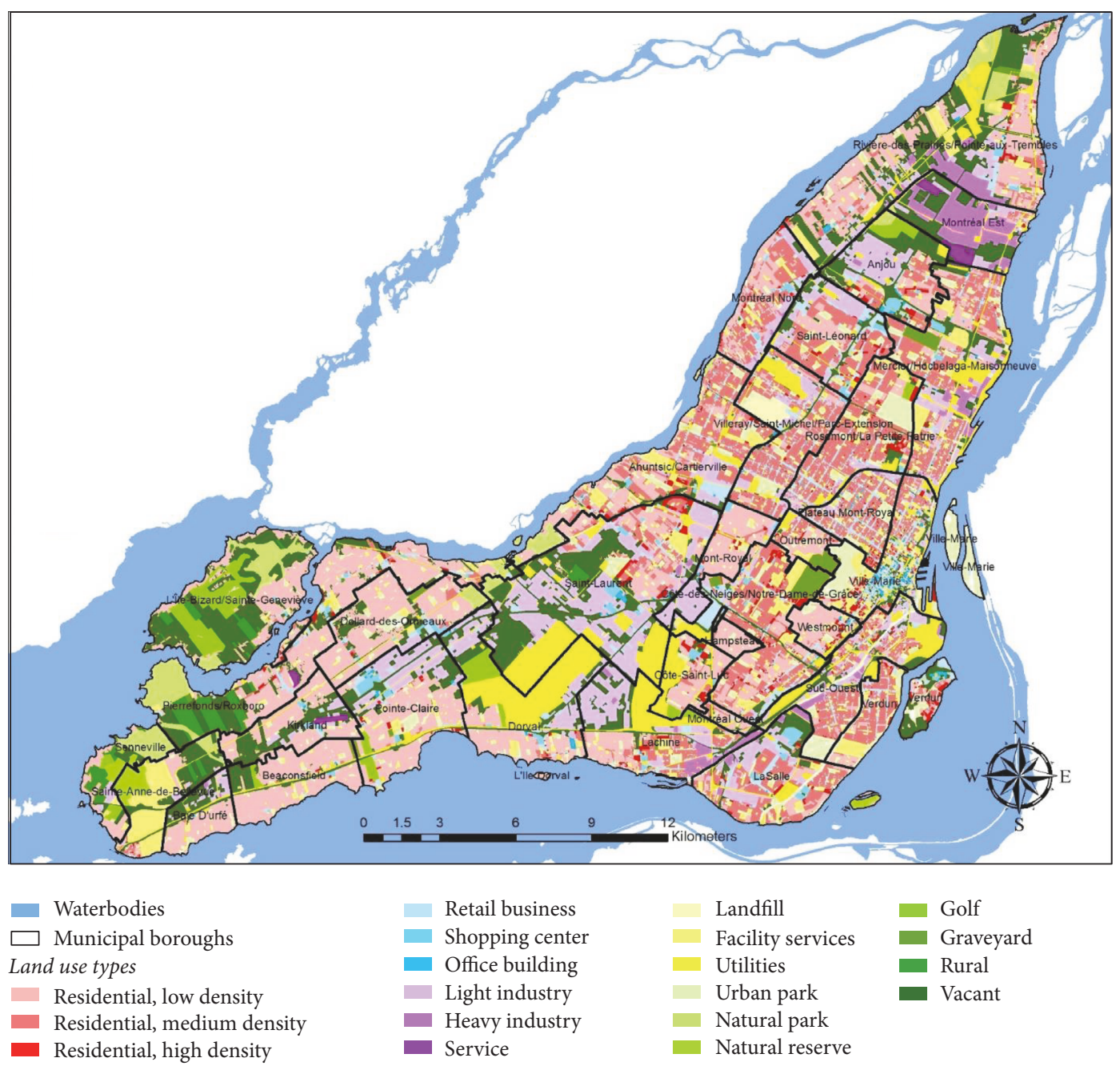

Figure 9: Different types of land uses in Montreal Island.

vehicles. Moreover, the levels of $\mathrm{NO}_{2}$ that vehicles emit vary according to time of day, season, and meteorological conditions. For example, levels of $\mathrm{NO}_{2}$ are higher in winter season than in other seasons because of the increased use of heating fuels.

The A-25 is the connecting highway between East Montreal and Laval and a significant number of freight traffic transit this highway; however, this study only simulated urban traffic ignoring the fright traffic during different scenarios. This study observes the reduction of levels of $\mathrm{NO}_{2}$ in 2013 comparing to that in 2003 despite the increase of traffic volume on the Montreal road network. This is because of increased modal share of public transit resulting from government's ongoing initiative to promote mass transit and reduce vehicle emissions as a part of Greater Montreal Area Transport Plan, 2000. Future studies can address this issue to identify the impact of government's strategy on vehicle emissions before, during and after the construction of A25 extension project. Future studies can also calibrate the vehicle emissions from simulated traffic and actual traffic counts.

\section{Conclusions}

This study finds out two outcomes from the spatial analyses of the levels of $\mathrm{NO}_{2}$ and traffic density for four scenarios. First, the levels of $\mathrm{NO}_{2}$ were increased in close proximity to the A-25 extension after its construction. Increase of $\mathrm{NO}_{2}$ concentrations resulted from the additional traffic. Second, the simulated traffic density for four scenarios explains that the traffic density was significantly increased, on both arterials and access roads within the close vicinity of the A-25 extension project during and after its construction.

This study justifies the concerns of the environmentalists on the potential air pollution from the additional traffic resulting from the construction of A-25 extension project. The outcomes of this study urge MTQ and other transport authorities to conduct environmental impact assessment before the construction of new road infrastructure. This study also suggests that transport authorities should assess other alternative solutions in order to reduce environmental degradation. Future studies require more detailed data on air pollutants emitted from the vehicles to understand the 


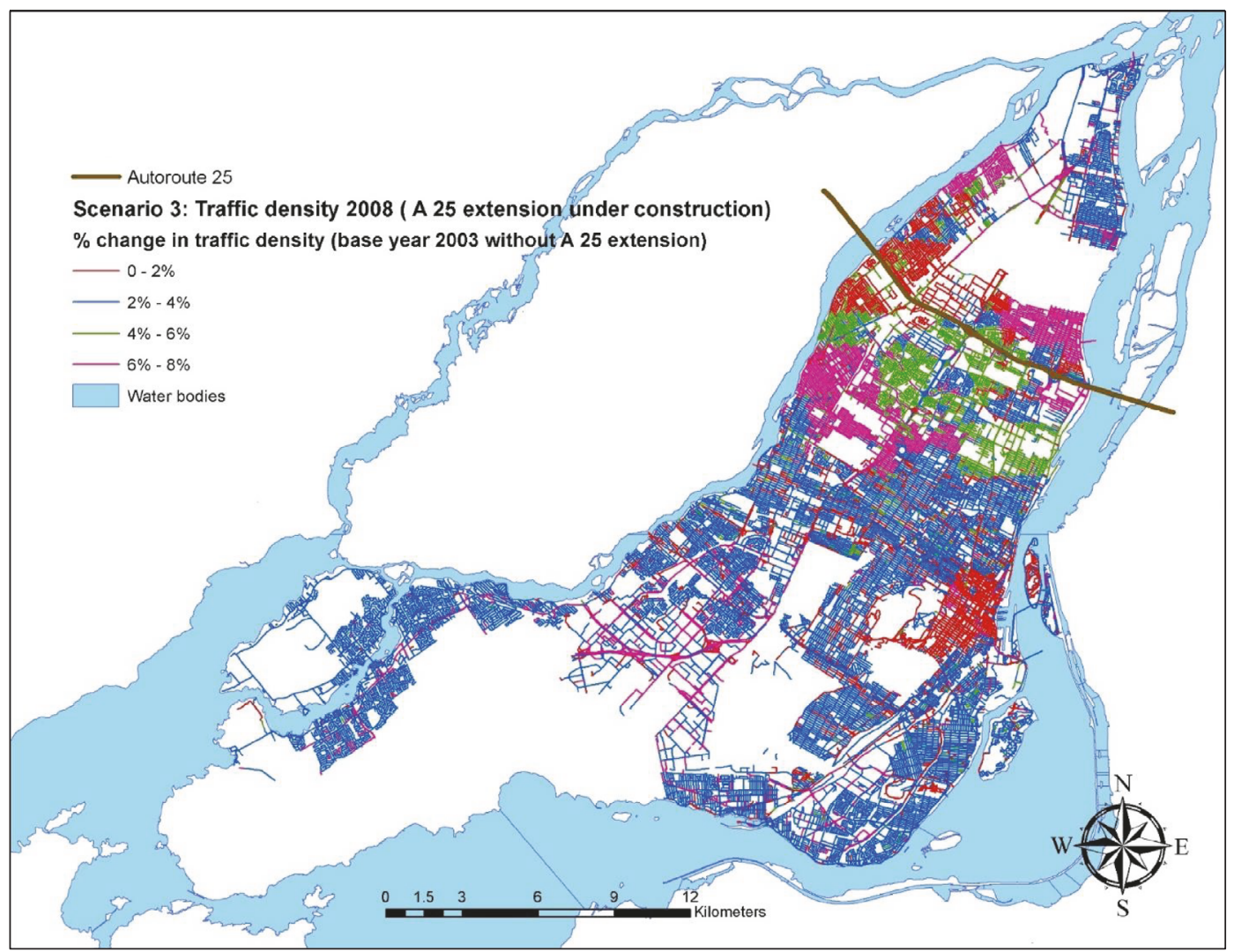

FIGURE 10: Percentage change in traffic density (vehicles per $\mathrm{km}$ ) at scenario 3 comparing to scenario 1.

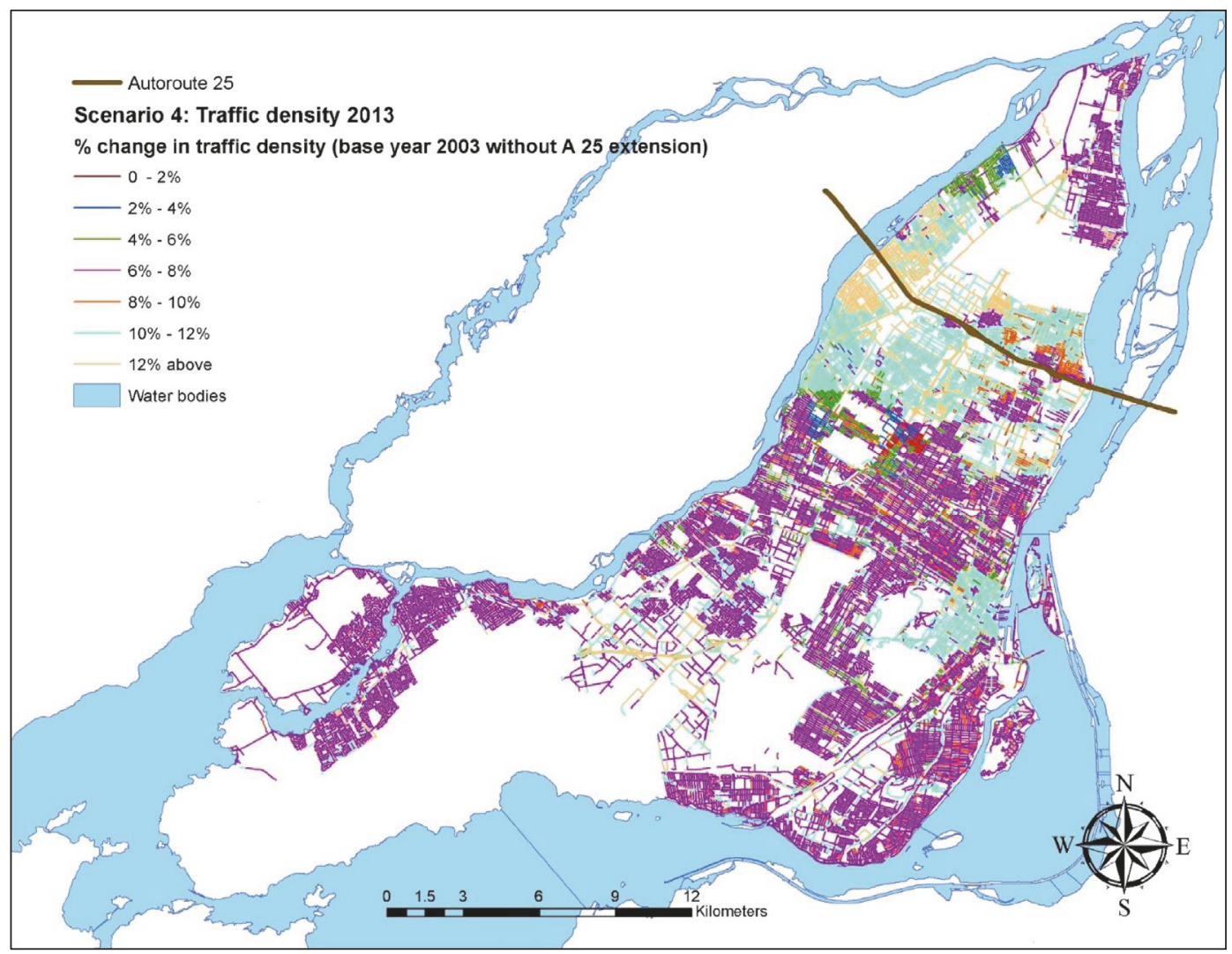

FIgURE 11: Percentage change in traffic density (vehicles per $\mathrm{km}$ ) at scenario 4 comparing to scenario 1. 
impact of additional traffic on the air quality rather than depending on the spatial interpolation of air records from available stations.

\section{Conflicts of Interest}

There are no conflicts of interest regarding this paper.

\section{References}

[1] Green Coalition. Highway 25: Memoire de la Coalition Verte, 2007, http://www.greencoalitionverte.ca/issues2007/Green\%20 Coalition\%20Brief\%20Oct\%202007.pdf.

[2] Groupe en Recheche Urbaine, Présenté à Concession A25 S.E.C. Consultations Publiques sur le projet de parachévement de l'highway 25, 2007, http://www.a25.com.

[3] M. Chiaburu, M. S. Diene, M. Dulgheru, and B. Kendrick, "Assessing the impact of the Highway 25 expansion project on air quality in Montreal using GIS," Geographia Napocensis, vol. IV, no. 1, pp. 49-60, 2010, http://geographianapocensis.acadcluj.ro/Revista/volume/nr_1_2010/pdf_uri/Chiaburu_D_.pdf.

[4] M. F. Mohamed, D. Kang, and V. P. Aneja, "Volatile organic compounds in some urban locations in United States," Chemosphere, vol. 47, no. 8, pp. 863-882, 2002.

[5] A. Antipova and C. Wilmot, "Alternative approaches for reducing congestion in Baton Rouge, Louisiana," Journal of Transport Geography, vol. 24, pp. 404-410, 2012.

[6] C. J. Sutton, "Land use change along Denver's I-225 beltway," Journal of Transport Geography, vol. 7, no. 1, pp. 31-41, 1999.

[7] W. Elias and Y. Shiftan, "The safety impact of land use changes resulting from bypass road constructions," Journal of Transport Geography, vol. 19, no. 6, pp. 1120-1129, 2011.

[8] W. Walton and J. Shaw, "Applying the new appraisal approach to transport policy at the local level in the UK," Journal of Transport Geography, vol. 11, no. 1, pp. 1-12, 2003.

[9] A. W. Coffin, "From roadkill to road ecology: A review of the ecological effects of roads," Journal of Transport Geography, vol. 15, no. 5, pp. 396-406, 2007.

[10] D. J. Briggs, C. De Hoogh, J. Gulliver et al., "A regression-based method for mapping traffic-related air pollution: Application and testing in four contrasting urban environments," Science of the Total Environment, vol. 253, no. 1-3, pp. 151-167, 2000.

[11] Y. Huang, R. Bird, and M. Bell, "A comparative study of the emissions by road maintenance works and the disrupted traffic using life cycle assessment and micro-simulation," Transportation Research Part D: Transport and Environment, vol. 14, no. 3, pp. 197-204, 2009.

[12] T. Wang and S. Xie, "Assessment of traffic-related air pollution in the urban streets before and during the 2008 Beijing Olympic Games traffic control period," Atmospheric Environment, vol. 43, no. 35, pp. 5682-5690, 2009.

[13] S. Bai, Y.-C. Chiu, and D. A. Niemeier, "A comparative analysis of using trip-based versus link-based traffic data for regional mobile source emissions estimation," Atmospheric Environment, vol. 41, no. 35, pp. 7512-7523, 2007.

[14] D. T. Ito, D. Niemeier, and G. Garry, "Conformity: How VMTspeed distributions can affect mobile emission inventories," Transportation, vol. 28, no. 4, pp. 409-425, 2001.

[15] T. Szentimrey, Z. Bihari, and S. Szalai, "Comparison of Geostatistical and Meteorological Interpolation Methods (What is
What?)," in Spatial Interpolation for Climate Data. The Use of GIS in Climatology and Meteorology, H. Dobesch, P. Dumolard, and I. Dyras, Eds., Geographical Information Systems Series, pp. 45-56, ISTE Ltd, London, UK, 2007.

[16] G. Ciotoli, S. Lombardi, and A. Annunziatellis, "Geostatistical analysis of soil gas data in a high seismic intermontane basin: Fucino Plain, central Italy," Journal of Geophysical Research: Solid Earth, vol. 112, no. 5, Article ID B05407, 2007.

[17] J. Erxleben, K. Elder, and R. Davis, "Comparison of spatial interpolation methods for estimating snow distribution in the Colorado Rocky Mountains," Hydrological Processes, vol. 16, no. 18, pp. 3627-3649, 2002.

[18] M. S. R. Amin and L. E. Amador-Jiménez, “Travel demand modeling to simulate traffic loads for pavement deterioration curves: Dealing with aggregate data at urban and regional scales," Canadian Journal of Civil Engineering, vol. 42, no. 12, pp. 1049-1062, 2015.

[19] Y. Sheffi and W. B. Powell, "An algorithm for the equilibrium assignment problem with random link times," Networks, vol. 12, no. 2, pp. 191-207, 1982.

[20] M. Maher, "Algorithms for logit-based stochastic user equilibrium assignment," Transportation Research Part B: Methodological, vol. 32B, no. 8, pp. 539-549, 1998.

[21] H. Yang, "Multiple equilibrium behaviors and advanced traveler information systems with endogenous market penetration," Transportation Research Part B: Methodological, vol. 32, no. 3, pp. 205-218, 1998.

[22] Y. Yin and H. Yang, "Simultaneous determination of the equilibrium market penetration and compliance rate of advanced traveler information systems," Transportation Research A, vol. 37, pp. 165-181, 2003.

[23] FHWA, Highway Performance Monitoring System Field Manual. Appendix N: Procedures for Estimating Highway Capacity, 2005, https://www.fhwa.dot.gov/ohim/hpmsmanl/appn7.cfm.

[24] F. L. Mannering and S. S. Washburn, Principles of Highway Engineering and Traffic Analysis, John Wiley \& Sons, Inc, Danvers, MA, USA, 5th edition, 2013. 


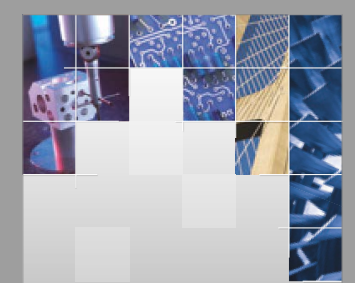

\section{Enfincering}
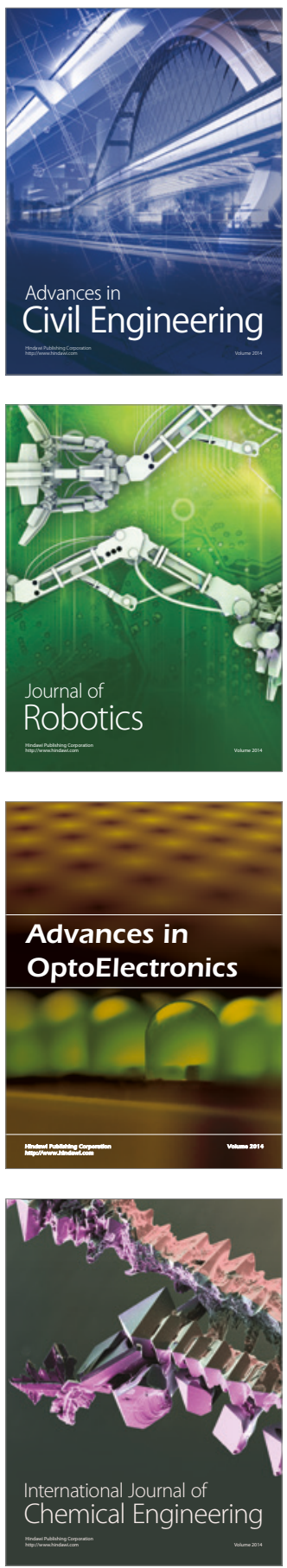

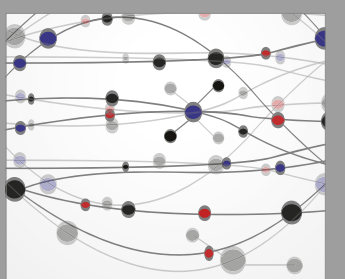

The Scientific World Journal

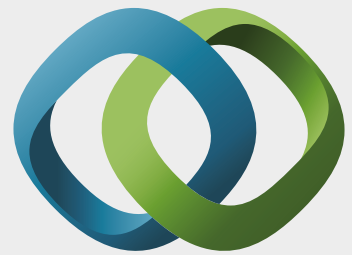

\section{Hindawi}

Submit your manuscripts at

https://www.hindawi.com
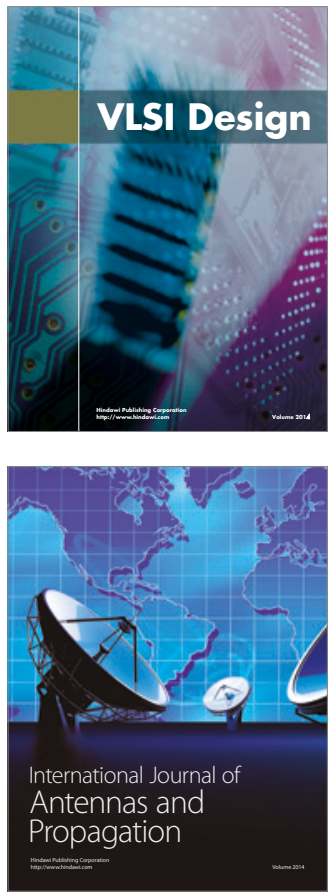

\section{Rotating}

Machinery
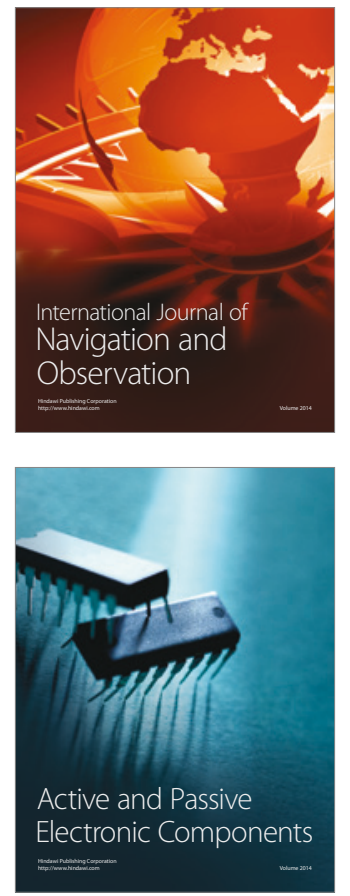
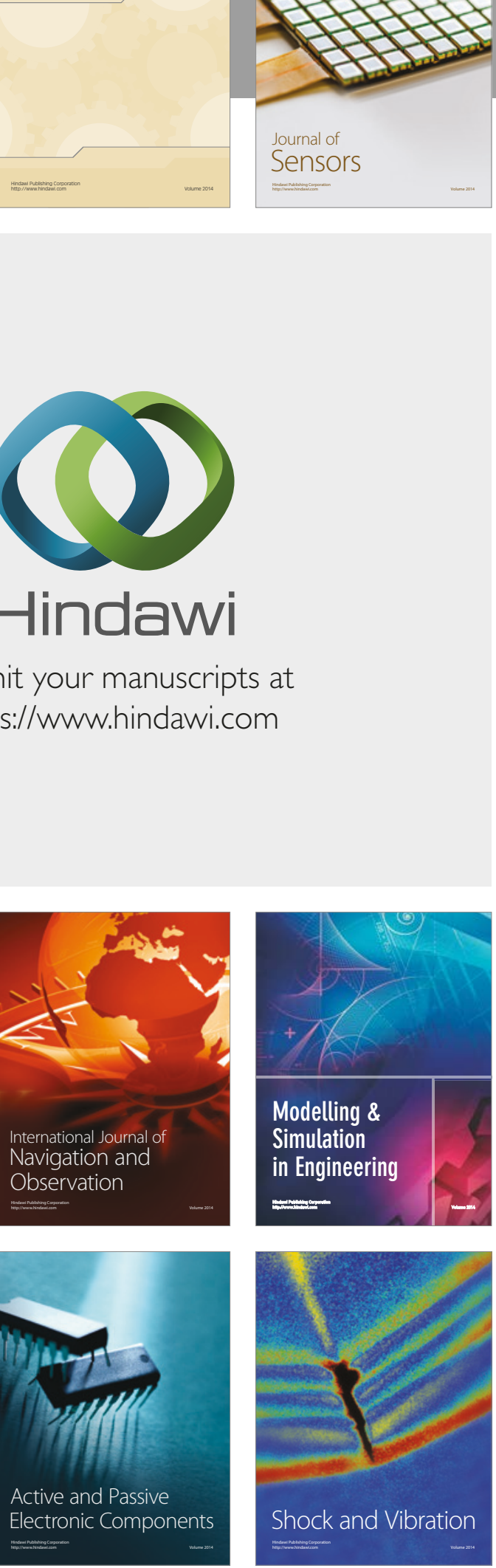
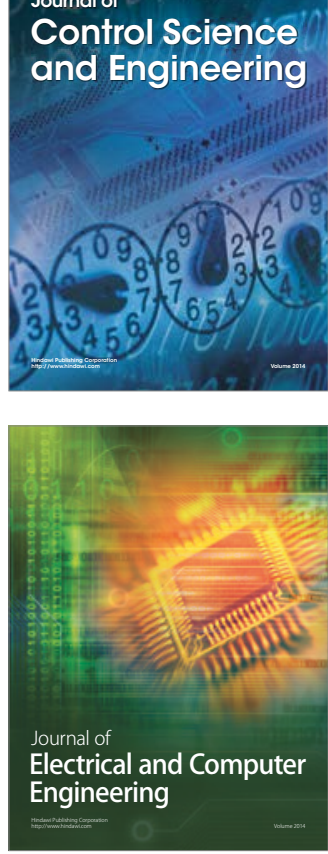

Distributed

Journal of

Control Science

and Engineering
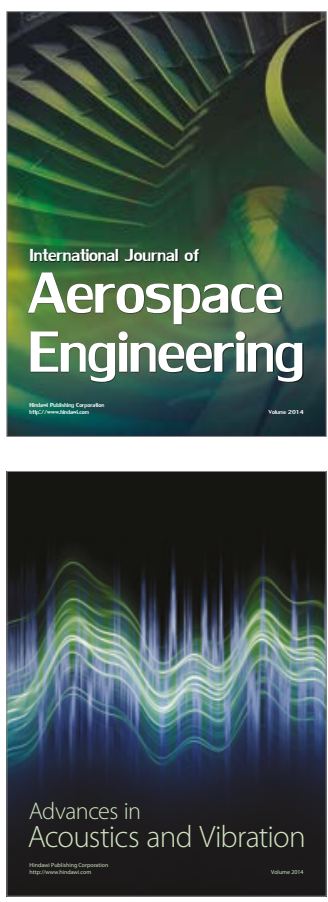

Sensor Networks 